\title{
Corrigendum: VIP Modulation of Hippocampal Synaptic Plasticity: A Role for VIP Receptors as Therapeutic Targets in Cognitive Decline and Mesial Temporal Lobe Epilepsy
}

\author{
Diana Cunha-Reis ${ }^{1,2 *}$ and Ana Caulino-Rocha ${ }^{1,2}$ \\ ${ }^{1}$ BiolSI - Biosystems and Integrative Sciences Institute, Faculdade de Ciências, Universidade de Lisboa, Lisbon, Portugal, \\ ${ }^{2}$ Departamento de Química e Bioquímica, Faculdade de Ciências, Universidade de Lisboa, Lisbon, Portugal
}

Keywords: VIP, synaptic plasticity, interneurons, hippocampus, MTLE, cognition, VPAC1 receptors

\section{A Corrigendum on}

VIP Modulation of Hippocampal Synaptic Plasticity: A Role for VIP Receptors as Therapeutic Targets in Cognitive Decline and Mesial Temporal Lobe Epilepsy

by Cunha-Reis, D., and Caulino-Rocha, A. (2020). Front. Cell. Neurosci. 14:153. doi: 10.3389/fncel.2020.00153

OPEN ACCESS

Edited and reviewed by: Lucia Ciranna,

University of Catania, Italy

*Correspondence: Diana Cunha-Reis

dcreis@ciencias.ulisboa.pt

Specialty section:

This article was submitted to

Cellular Neurophysiology,

a section of the journal

Frontiers in Cellular Neuroscience

Received: 07 April 2021 Accepted: 12 April 2021 Published: 14 May 2021

Citation: Cunha-Reis D and Caulino-Rocha $A$ (2021) Corrigendum: VIP Modulation of Hippocampal Synaptic Plasticity: A Role for VIP Receptors as Therapeutic Targets in Cognitive Decline and Mesial Temporal Lobe Epilepsy. Front. Cell. Neurosci. 15:691978. doi: 10.3389/fncel.2021.691978
In the original article, there was a mistake in Figure 1 as published. Circuits on the left side of the Figure moved down and stretched and do not represent what is described in the text for VIP O/A interneurons and their targets, OLM cells that should have their cell body in the stratum oriens. The corrected Figure 1 appears below.

Additionally, in the original article, there was an error in the identification of type II IS cells (a different nomenclature for a subpopulation (and not all) of VIP+ interneurons projecting to the stratum radiatum).

A correction has been made to section VIP in the Hippocampus, Second Paragraph.

The corrected paragraph is shown below.

Detailed immunohistochemistry studies fully characterized hippocampal $V I P^{+} I N s$ dendritic trees and axon projections (Acsády et al., 1996a,b), allowing the classification of VIP ${ }^{+} I N s$ into two fundamental groups according to their targets: $V I P^{+}$basket cells are responsible for somatic inhibition of pyramidal cells, are also immunoreactive for cholecystokinin $\left(V I P^{+}\right.$$C C K^{+} B C s$, Figure 1) and do not express parvalbumin, as most $B C s$ in the hippocampus. $V I P^{+} I N s$ that selectively innervate other interneurons (VIP ${ }^{+} I S I N s$ ) include two subtypes: (a) interneurons with cell bodies located at the stratum pyramidale (SP) or near and projecting to the stratum Oriens/Alveus border (VIP ${ }^{+}$IS O/A INs or type III IS cells, Figure 1), that also express the interneuron marker calretinin and target mostly somatostatin-expressing $\left(\mathrm{SOM}^{+}\right)$ oriens lacunosum-moleculare (OLM) interneurons innervating the distal dendrites of pyramidal cells at the stratum lacunosum-moleculare (SLM) and (b) VIP ${ }^{+}$INs that project their axons to the stratum radiatum ( $S R, V I P^{+} I S S R I N$ s, Figure 1), with cell bodies located either at the $S R / S L M$ border (type II IS cells) or at $S R / S P$ and targeting interneurons controlling synaptic transmission to proximal dendrites of pyramidal cells in the SR (Acsády et al., 1996a,b; Klausberger and Somogyi, 2008). In genetically modified VIP-eGFP mice, additional targets of VIP+ IS O/A INs in the O/A, 


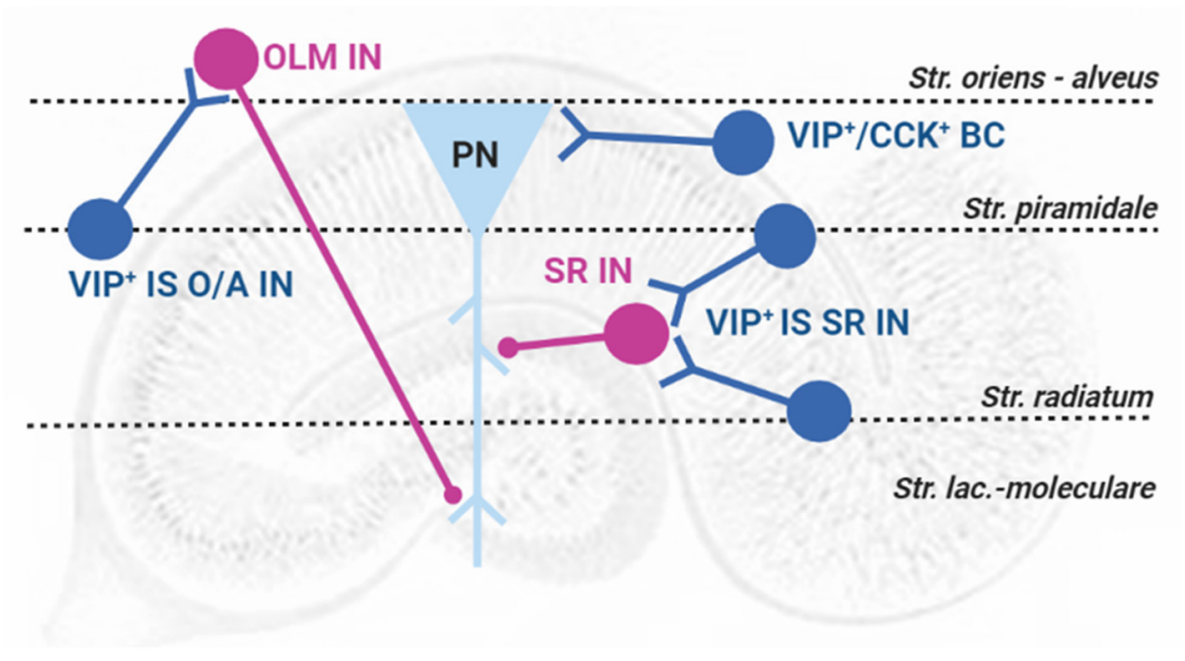

FIGURE 1 | Representation of VIP-containing interneurons in the rat hippocampus: layer location and target selectivity. PN, pyramidal neuron (triangle, light blue); Interneurons (circles, pink); VIP-containing interneurons (circles, blue); VIP+ ${ }^{+} C C K^{+} B C s$ : VIP-containing basket cells; VIP+ IS O/A IN: VIP-containing interneuron-selective interneuron targeting the stratum oriens/Alveus and VIP+ IS SR IN: VIP-containing interneuron-selective interneuron targeting the stratum radiatum; OLM IN - Stratum oriens interneuron projecting to the Stratum lacunosum-moleculare; SR IN - Stratum radiatum local interneurons. Str.: stratum.

including bistratified cells and oriens-oriens INs, have been described and recently a new VIP expressing interneuron population located at the $\mathrm{O} / \mathrm{A}\left(V I P^{+}\right.$long-range projecting INs, $V I P^{+}$LRP INs) was described targeting INs within the $\mathrm{O} / \mathrm{A}$ in CA1 but also both INs and pyramidal cells within the subiculum

\section{REFERENCES}

Acsády, L., Arabadzisz, D., and Freund, T. F. (1996a). Correlated morphological and neurochemical features identify different subsets of vasoactive intestinal polypeptide-immunoreactive interneurons in rat hippocampus. Neuroscience 73, 299-315. doi: 10.1016/0306-4522(95)00610-9

Acsády, L., Görcs, T. J., and Freund, T. F. (1996b). Different populations of vasoactive intestinal polypeptide-immunoreactive interneurons are specialized to control pyramidal cells or interneurons in the hippocampus. Neuroscience 73, 317-334. doi: 10.1016/0306-4522(95)00609-5

Francavilla, R., Villette, V., Luo, X., Chamberland, S., Muñoz-Pino, E., Camiré, O., et al. (2018). Connectivity and network state-dependent recruitment of long-range VIP-GABAergic neurons in the mouse
(Francavilla et al., 2018). It is not clear if it is also present in the rat hippocampus.

The authors apologize for these errors and state that they do not change the scientific conclusions of the article in any way. The original article has been updated.

hippocampus. Nat. Commun. 9:5043. doi: 10.1038/s41467-018-07 162-5

Klausberger, T., and Somogyi, P. (2008). Neuronal diversity and temporal dynamics: the unity of hippocampal circuit operations. Science 321, 53-57. doi: 10.1126/science.1149381

Copyright (C) 2021 Cunha-Reis and Caulino-Rocha. This is an open-access article distributed under the terms of the Creative Commons Attribution License (CC BY). The use, distribution or reproduction in other forums is permitted, provided the original author(s) and the copyright owner(s) are credited and that the original publication in this journal is cited, in accordance with accepted academic practice. No use, distribution or reproduction is permitted which does not comply with these terms. 